\title{
Evaluation of Endovascular Intervention Therapy Results in Chron- ic Below-The-Knee (BTK) Arterial Occlusive Disease
}

\author{
Le Duc Tin*, Nut Lam Van, Anh Pham Minh \\ Vascular Surgery Department, Cho Ray Hospital, Ho Chi Minh City, Vietnam
}

"Corresponding author: Tin Duc Le, Department of Vascular Surgery, Cho Ray Hospital, District 5, Vietnam. Tel: +84903020359; Email:dr.ductin@gmail.com

Citation: Tin LD, Van NL, Minh AP (2017) Evaluation of Endovascular Intervention Therapy Results in Chronic Below-The-Knee (BTK) Arterial Occlusive Disease. Cardiolog Res Cardiovasc Med 2: 125. DOI: 10.29011/2575-7083.000025

Received Date: 23 October, 2017; Accepted Date: 28 October, 2017; Published Date: 04 November, 2017

\begin{abstract}
Objective: To evaluate the results of endovascular intervention therapy in Below-The-Knee (BTK) arterial disease.

Methods: Retrospective descriptive series of cases. We had researched from January 2015 to May 2017 at Vascular Surgery department in Cho Ray hospital.

Results: The study sample of 80 patients. We had counted $56.3 \%$ female rates, average ages $74.4 \pm 11.4$. Chief complain symptom was a painfully, $53.8 \%$ sample. Percutaneous transluminal angioplasty (PTA) performed by $76.25 \%$, PTA and stent replacement combination accounted for $23.75 \%$. BTK intervention simple accounted for $36.3 \%$, other combination was $63.7 \%$. The procedure times had $124 \pm 39.8$ minutes. The time of hospitalization average was $4 \pm 2.7$ days. Total complication was $3.8 \%$ samples with thrombosis had got into $2.5 \%$, hematoma had got $2.5 \%$, amputation had got $1.25 \%$ and mortality rate had got 1 case in our research. Technique and short-term results success rates were $85 \%$ and $77.5 \%$, respectively.
\end{abstract}

Conclusions: The intervention endovascular therapy of chronic arterial occlusion of the lower extremity less invasive method which is safe, effective, shorter hospital stays and faster recovery of patients. Results of short-term achieve a high success rate.

Keywords: Arterial Occlusive Disease; Below-TheKnee (BTK); Endovascular Intervention; Peripheral Artery Disease

\section{Introduction}

BTK artery disease with vessels of small diameter, the blood flow come in so far. When the disease has been covered, there is usually evidence of severe anemia. Previously, this disease was bypassed, which was a heavily operation that was not effectively. Especially in elderly patients, many factors increase the risk of surgery with ineffectively outflow, or small veins that was difficult to used bypass surgery. Following the success of endovascular intervention for peripheral vascular disease, BTK intervention initially provides positive signs.

AtCho Ray Hospital, in 2012, we initiative has treated patients with peripheral artery diseases by endovascularintervention: Percutaneous Transluminal Angioplasty (PTA), stent placement initially results in satisfactory. The number of patients with chronic obstructive artery diseases came to treatment with this technique was increasing, from 39 cases in 2013 to 197 cases in 2015. However, there are still little research projects in our country. Therefore, the purpose of our study evaluated the results of endovascular intervention therapy chronic Below- The- Knee (BTK) arterial occlusive disease.

\section{Research Methods}

Study design: Retrospective descriptive study.

Time study: sampling from January 2015 to May 2017.

Research area: Cho Ray Hospital.

Study subjects: [1]

\section{Standard sampling:}

All these cases have BTK artery disease whom admitted Vascular Surgery department. They had performed endovascular intervention. 


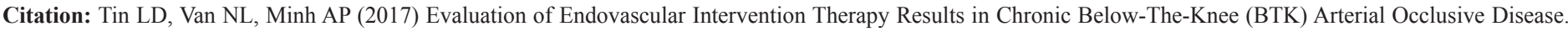
Cardiolog Res Cardiovasc Med 2: 25. DOI: 10.29011/2575-7083.000025

\section{Exclusion criteria:}

Bypass surgery.

Hybrid procedure.

Upper the knee artery diseases haven't revascularize yet or not revascularize enough (upper the knee arteries diameter after $\left.{ }^{3} 70 \%\right)$.

\section{Evaluating the results of treatment:}

- Evaluation of a successful outcome based interventions: clinical, subclinical [2].

\begin{tabular}{|c|c|}
\hline $\begin{array}{l}\text { Clinical (Rutherford } \\
\text { category) }\end{array}$ & $\begin{array}{l}\text { Improvement in baseline symptoms by at least } 1 \\
\text { category }\end{array}$ \\
\hline Ultrasound & $\begin{array}{l}>70 \% \text { reduction in luminal diameter suggested by } \\
\text { PSVR }^{3} 3.0\end{array}$ \\
\hline ABI & Increase of $>0.15$ \\
\hline
\end{tabular}

-Evaluate the results at 2 times intervention: immediately after surgery, 01 months.

\section{Results}

The sample had 09 cases of patients met the inclusion criteria.

- Age, Gender and Risk Factors, Diseases Combinations:

\begin{tabular}{|c|c|c|}
\hline & N $(\%)$ & Mean \\
\hline Age & $74(100 \%)$ & $74.41 \pm 11.4(43-92)$ \\
\hline Dyslipidaemia & $57(71.3 \%)$ & \\
\hline Hypertension & $43(53.8 \%)$ & \\
\hline Smoking & $41(51.2 \%)$ & \\
\hline Diabetes & $34(42.5 \%)$ & \\
\hline Carotid & $16(20 \%)$ & \\
\hline Stroke & $9(13.3 \%)$ & \\
\hline Renal failure & $7(8.8 \%)$ & \\
\hline
\end{tabular}

\begin{tabular}{|c|c|l|}
\hline CAD & $4(5 \%)$ & \\
\hline Heart failure & $3(3.8 \%)$ & \\
\hline Cirrhosis & $0(0 \%)$ &
\end{tabular}

Table 1.1: Age, Gender and Risk Factors, Disease Collaboration.

- Rutherford Category:

\begin{tabular}{|c|cc|c|}
\hline Stages & Category & N (\%) before & N (\%) after \\
\hline 0 & 0 & $0(0 \%)$ & $0(0 \%)$ \\
\hline \multirow{3}{*}{} & 1 & $0(0 \%)$ & $5(6.3 \%)$ \\
\cline { 2 - 4 } & 2 & $2(2.5 \%)$ & $4(5 \%)$ \\
\cline { 2 - 4 }
\end{tabular}

\begin{tabular}{|c|c|c|c|}
\hline & 3 & $6(7.5 \%)$ & $18(22.5 \%)$ \\
\hline II & 4 & $13(16.3 \%)$ & $23(28.7 \%)$ \\
\hline III & 5 & $18(22.5 \%)$ & $19(23.8 \%)$ \\
\hline IV & 6 & 41 (51.2\%) & $11(13.8 \%)$ \\
\hline Total & & $80(100 \%)$ & $80(100 \%)$ \\
\hline
\end{tabular}

Table 1.2: Rutherford Category.

- TASC II classification:

\begin{tabular}{|c|c|}
\hline Stages & $\mathrm{N}(\%)$ \\
\hline A & $0(0 \%)$ \\
\hline B & $3(3.8 \%)$ \\
\hline C & $26(32.5 \%)$ \\
\hline D & $51(63.7 \%)$ \\
\hline Total & $80(100 \%)$ \\
\hline
\end{tabular}

Table 1.3: TASC II classification.

- The relationship between TASC II with clinical symptoms:

\begin{tabular}{|c|c|c|c|}
\hline & & IC & CLI \\
\hline \multirow{4}{*}{} & A & $0(0 \%)$ & $0(0 \%)$ \\
\cline { 2 - 4 } & B & $1(1.25 \%)$ & $2(2.5 \%)$ \\
\cline { 2 - 4 } & $\mathrm{C}$ & $10(12.5 \%)$ & $1620 \%)$ \\
\cline { 2 - 4 } & $\mathrm{D}$ & $1(1.25 \%)$ & $50(62.5 \%)$ \\
\hline Total (\%) & & $12(15 \%)$ & $68(85 \%)$ \\
\hline
\end{tabular}

Table 1.4: The relationship between TASC II with clinical symptoms:

\section{Result}

- Anaesthesia

\begin{tabular}{|c|c|c|}
\hline & $\mathrm{N}$ & $\%$ \\
\hline Endotracheal & 1 & 1.25 \\
\hline Spinal & 0 & 0 \\
\hline Local & 79 & 98.75 \\
\hline Total & 80 & 100 \\
\hline
\end{tabular}

Table 1.5: Anaesthesia

- The Approach Way

\begin{tabular}{|c|c|c|}
\hline & $\mathrm{N}$ & $\%$ \\
\hline Antegrade & 80 & 100 \\
\hline Retrograde & 0 & 0 \\
\hline Total & 80 & 100 \\
\hline
\end{tabular}

Table 1.6: The Approach Way

- Endovascular Methods 
Citation: Tin LD, Van NL, Minh AP (2017) Evaluation of Endovascular Intervention Therapy Results in Chronic Below-The-Knee (BTK) Arterial Occlusive Disease. Cardiolog Res Cardiovasc Med 2: 25. DOI: 10.29011/2575-7083.000025

\begin{tabular}{|c|c|c|}
\hline & $\mathrm{N}$ & $\%$ \\
\hline PTA & 61 & 76.25 \\
\hline Stent & 0 & 0.0 \\
\hline PTA+ Stent & 19 & 23.75 \\
\hline Total & 80 & 100 \\
\hline
\end{tabular}

Table 1.7: Endovascular Methods

\section{- Limbs Intervention}

\begin{tabular}{|c|c|c|}
\hline Limbs & $\mathrm{N}$ & $\%$ \\
\hline 01 limbs & 80 & 100 \\
\hline 02 limbs & 0 & 0 \\
\hline Total & 80 & 100 \\
\hline
\end{tabular}

Table 1.8: Limbs Intervention

\section{- $\quad$ Floor Intervention}

\begin{tabular}{|c|c|c|}
\hline Floor intervention & $\mathrm{N}$ & $\%$ \\
\hline BTK & 29 & 36.3 \\
\hline FP+BTK & 44 & 55 \\
\hline Iliac+BTK & 3 & 3.8 \\
\hline Iliac+FP+BTK & 4 & 5 \\
\hline Total & 80 & 100 \\
\hline
\end{tabular}

Table 1.9: Floor Intervention

\section{- Length of hospital stay (LOS), Intervention time}

\begin{tabular}{|c|c|}
\hline Time & Mean \\
\hline Intervention time(min) & $124 \pm 39.8(45-230)$ \\
\hline LOS(day) & $4 \pm 2.7(1-18)$ \\
\hline
\end{tabular}

Table 1.10: Length of hospital stay(LOS), Intervention time.

\section{- Complication}

\begin{tabular}{|c|c|c|c|c|c|c|c|c|}
\hline & \multicolumn{9}{|c|}{ complication } \\
\cline { 2 - 8 } & Occlusion & Hematoma & Amputation & Fistula & $\begin{array}{c}\text { Pseudoaneu- } \\
\text { rysm }\end{array}$ & Penetrated & MI & Died \\
\cline { 2 - 8 } & $\mathbf{2}$ & $\mathbf{2}$ & $\mathbf{1}$ & $\mathbf{0}$ & $\mathbf{0}$ & $\mathbf{1}$ & $\mathbf{1}$ \\
\hline Total N (\%) & \multicolumn{7}{|c|}{$\mathbf{3}(\mathbf{3 . 7 5 \% )}$} \\
\hline
\end{tabular}

Table 1.11: Postintervention Complication

\section{- Intervention Results}

\begin{tabular}{|c|c|c|}
\hline Results & Success & Fail \\
\hline Post $(n=80)$ & $85 \%(68)$ & $15 \%(12)$ \\
\hline Short-term $(n=80)$ & $77.5 \%(62)$ & $22.5 \%(18)$ \\
\hline
\end{tabular}

Table 1.12: Intervention Results

\section{Discussion}

In the study, we found a high proportion of women than men. Our sample reported smoking 41 cases, got 51.2\% samples, lipid metabolism disorders has 57 cases, got $71.3 \%$ samples. According to other documents [2,3], smoking and lipid metabolic disorders becomes a factor accelerating the process of pathological blood vessels, increases the severity of the disease and significant impact on disease chronic arterial occlusion of the lower extremities.

The Main Symptom: Is pain hospitalized patients, accounting for $53.8 \%$ with severe clinical manifestations, recorded most cases classified under Rutherford 5, 6 degrees, 73.7\% accounted for. Of these, 41 cases, accounting for $51.2 \%$ of the samples studied had ulcers or gangrene. In the study sample, only recorded lesions TASC II C and D accounted for $32.5 \%$ and 63.7 respectively $\%$. As recommended by the 2nd update TASC (Transatlantic InterSociety Consensus) [4], those to TASC II C may be surgery or intervention, while the TASC II D lesions should surgery. However, in this group, older patients, combining multiple severe medical conditions, are at high risk cannot perform surgery. Therefore, we carried out interventions for this patient population, initial positive results.

The Method of Anaesthesia: Local anaesthesia got 98.7\% sample. These are the advantages of endovascular interventions. After the intervention, the patient recovers faster and avoid complications of anaesthesia. This is very heavy on older patients, patient coordination. Interventions: Mostly PTA method, accounting for $76.25 \%$ of the sample studied. PTA combined stent replacement a low percentage, $23.75 \%$ of the sample studied. We have not recorded any case in stent replacement simply. This shows that the question is not the first choice for stent replacement in BTK intervention. Because of the characteristics of blood vessels BTK is the small blood vessels, extend stenosis lesions, low flow is at risk or restenosis after stent replacement. However, because the study sample was small, the study design was not strong enough, so we thought should be studied in more detail on this issue because there is evidence that stent replacement still effective $[5,6]$. On the other hand, according to other authors [7-9], PTA with balloon drug is also positive results in the form that this study does not have to be.

We intervene mainly BTK floor, accounting for $36.3 \%$, coordinating BTK occupied 55\% femoro- popliteal floor. All the cases we intervene 1 limb. Intervention time average 124 minutes, the average length of hospital stay 05 days.Complications Interven- 


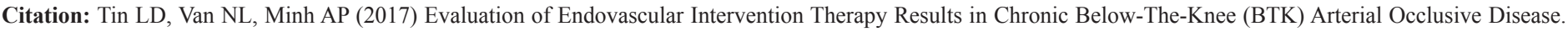
Cardiolog Res Cardiovasc Med 2: 25. DOI: 10.29011/2575-7083.000025

tion: We had 03 cases with $3.75 \%$ sample studied. Including 01 cases of hematoma at the needle position, we must proceed hematoma surgically removed; there are 01 cases of embolism after intervention leg to amputation of the lower $1 / 3$ of the left thigh. There are 01 cases of embolism, penetrated and hematoma at the right calf, we need to perform removal hematoma, fasciotomy.

Evaluate the Results: Endovascular intervention method merely succeeded lower limb reperfusion achieve good results, with success rates of $85 \%$ technical. Results in the period accounted for $77.5 \%$ short term. We found that the intervention time and length of hospital stay in our study sample longer than the other authors $[5,8]$. However, this is the first phase we performed to intervene which should not have much experience and equipment are limited. Endovascular interventions have significantly improved clinical symptoms, subclinical in the short term. Once again confirms the effectiveness of this approach to patients with chronic below-the-knee arterial occlusive diseases. Especially older patients, with severe medical conditions, high risk factors.

\section{Conclusion}

By studying 80 cases of chronic below-the-knee arterial occlusive diseases were treated with endovascular interventions, we have concluded the following:

- Patients who are almost the same between men and women, elders have many risk factors and diseases coordination.

- Patients with severe clinical presentation with symptoms of critical limbs ischemia, TASC II C and D classification.

- Shorter length of hospital stayed and faster recovery of patients.

- Endovascular intervention is less invasive methods, technical success accounted for $85 \%$ and short-term results accounting for $77.5 \%$.

\section{References}

1. Overhagen H Van, Tsetis D (2013) CIRSE standards of practice guidelines: Below-the- knee Interventions. Cardiovasc Intervent Radiol 36: 302-311.

2. Sobieszczyk P, Eisenhauer A (2013) Management of patients after endovascular interventions for peripheral artery disease. Circulation 128: 749-757.

3. Joseph L Mills, David G Armstrong, Pomposelli FB, Schanzer A, Sidawy AN, et al. (2014) The Society for Vascular Surgery Lower Extremity Threatened Limb Classification System: risk stratification based on wound, ischemia, and foot infection (WIfI). J Vasc Surg 59: 220-234.

4. Michael R Jaff C, William R Hiatt (2015) An Update on Methods for Revascularization and Expansion of the TASC Lesion Classification to Include Below-the-Knee Arteries: A Supplement to the Inter-Society Consensus for the Management of Peripheral Arterial Disease (TASC II). Journal of Endovascular Therapy: 657-571.

5. Andrew J Feiring, Amy A Wesolowski, Lade S (2004) Primary Stent-Supported Angioplasty for Treatment of Below-Knee Critical Limb Ischemia and Severe Claudication: Early and One-Year Outcomes. Journal of the American College of Cardiology 44: 2307-2314.

6. Bruce H Gray, Robert S Dieter, Michael R Jaff, Christopher J White (2014) SCAI Expert Consensus Statement for Infrapopliteal Arterial Intervention Appropriate Use. Catheterization and Cardiovascular Interventions 84: 539545.

7. Daniel Brandão, Armando Mansilha (2012) Below the Knee Techniques: Now and Then, Angioplasty, Various Techniques and Challenges in Treatment of Congenital and Acquired Vascular Stenoses, In Tech, Europe, Chap 3: 41-58.

8. Francesco Liistro, Paolo Angioli, Grotti S, Ricci L, Ducci K, et al. (2013) DrugEluting Balloon in Peripheral Intervention for Below the Knee Angioplasty Evaluation (DEBATE-BTK). Interventional Cardiology 128: 615-621.

9. Marco Manzi (2012) Revascularization of Tibial and Foot Arteries: Below the Knee Angioplasty for Limb Salvage", Angioplasty, Various Techniques and Challenges in Treatment of Congenital and Acquired Vascular Stenoses, InTech, Europe, Chap 10: 210-232. 